\title{
PRINCIPAL'S LEADERSHIP STYLE, AS PERCEIVED BY TEACHERS, IN RELATION TO TEACHER'S EXPERIENCE FACTOR OF SCHOOL CLIMATE IN ELEMENTARY SCHOOLS
}

\section{Gabriel Pinkas ${ }^{1}$ Aid Bulić}

Faculty of Philosophy, University of Tuzla

\author{
Original scientific paper \\ DOI:10.21554/hrr.091705
}

Received: 02.08.2017

Accepted: 05.09.2017

\begin{abstract}
The experience of the environment in which the activity is performed is a significant factor of the outcome of this activity, that is, the efficiency of the work and the degree of achieving the goal. Within the work environment, physical and social conditions can be observed. The first, which includes material and technical means, are mostly static, easily perceivable and measurable. Others, which include social relations, are much more susceptible to change, more difficult to perceive and measure, and their experience with different individuals within the same group can be more distinct. Although all members of the group participate in group dynamics and relationships, not all are equally relevant to these processes. Considering the position that carries the right and responsibility of setting up a vision and mission, setting goals, creating conditions for work, making decisions and providing feedback, the leader is in most cases crucial. This paper analyzes the role of elementary school principals in creating a school climate, as a non-material environment in which educational activity is carried out, and in this sense it is a specific group / work organization. An estimate was used to measure both variables, i.e. teacher's experience. The instruments used are Multifactor Leadership Questionnaire - MLQ (Avolio and Bass) and School Level Environment Questionnaire - SLEQ (Johnson, Stevens and Zvoch). The survey was conducted in elementary schools in the wider city area of Tuzla, on a sample of 467 teachers and 25 principals. In statistical data processing, multiple regression (Ordinary least squares) and direct square discriminatory analysis were applied. The obtained results point to the connection between the perceived leadership style of elementary school principals and the school climate experienced by teachers, especially in the field of innovation in teaching and mutual cooperation.
\end{abstract}

Keywords: leadership style; transformational, transactional, laissez-faire leadership; school climate.

\section{INTRODUCTION}

Although leadership as a social phenomenon is very old, the attempt to scientifically describe and understand it is relatively new. A manager or leader is a person who, in his words and / or personal example, influences the behavior, thoughts and / or emotions of a significant number of people. Leadership is discussed in the context of politics, working organizations, and all other social groups.

Among the earliest studies in this field are the study of Lewin, Lippith and White (1939), which pointed to differences in work achievement between groups with different leaders. In the medium and long term, the conclusions of the three authors, the best results are obtained by the democratic behavior of the leader. In the short term, the most effective is autocratic, while Laissez-faire leadership in most cases leads to the lowest achievement (Krech, Crutchfield \& Ballachey, 1969).

\footnotetext{
${ }^{1}$ Correspodence to:

Gabriel Pinkas, Faculty of Philosophy, University of Tuzla

Dr. Tihomila Markovića no.1, Tuzla, Bosnia and Herzegovina

Tel: +38761315904

E-mail: gabriel.pinkas@untz.ba
} 
This classical division into three leadership styles in subsequent research has undergone some changes; styles have, in some cases, been given different names, sometimes they are somewhat different described, and it is indicated on their transitional variants. Nevertheless, differences in interpersonal relations (relationship leader - employee and employer - employee), emotional, social and working climate, and work performance in groups with different leaders (Bojanović, 2004) remained as constant.

B. M. Bass introduced his theory of leadership in 1985. He talks about transformational, transactional and Laissez-faire leadership. The first contains elements of democratic and the second elements of the autocratic style. Particularly significant for transformational leadership, according to Avoliu and Bass (2002), is that it leads to a change in the very employees; raises the level of motivation and morally shapes them. In contrast, transaction leadership is based on the relation "give and take", in which everyone stays in the starting positions; neither individuals nor interpersonal relations change. Laissez-faire style Avolio and Bass (2002) describe almost the same as Lewin, Lippit and White (1939); it's free leadership. Avolio and Bass also call it passive / avoiding leadership. Although the school in the form in which we know it today appeared much earlier, the interest of researchers in the field of pedagogy to perceive each institution as a separate institution / community, which has its own history, (in part) its own system of values, the specific relations of its members, and represents a unique social, emotional and working environment, takes swings from the sixties of the last century. Namely, then, the approach to analyze the laws that are equally valid in all schools is left, and emphasis is placed on the importance that hardly visible and intangible factors have in achieving the goals and tasks of the school. Common to all research from that time, which is mostly the case today, is climate measurement based on perception, or description of school life by teachers and / or pupils (Domović, 2004).

At the same time, the issue of climate is perceived at different levels of organization (school, department) and in different segments of school work (teaching, extracurricular activities). Then, the notion of climate is shifting to the social, emotional and working component, and in our speaking area, with the word climate, the words, atmosphere, tone, spirit, mood, environment, ambience are used, among others. All this has led to very varied and unconstrained terminology, and in the literature terms can be found such as school climate, class climate, teaching climate, social climate, emotional climate, working climate, psychosocial climate and pedagogical climate. Some of these terms are used as synonyms, although this is not always emphasized, while some have a different meaning. However, clear conceptual delineations are rare. Understanding is further complicated by the use of the term of culture, which in some studies is identified with the term climate, while in others it is clearly separated.

\section{Principals as school leaders}

Principals are school leaders, responsible for achieving mission and goals of the school. Pedagogical standards and general norms for primary education (2005) refer to more than 80 tasks performed by the principals and which are divided into the following areas:

1. conceptual - program tasks

2. organizational - material problems

3. pedagogical-instructive work

4. analytical-study work

5. normative legal and financial affairs

6. representing the school

7. pedagogical documentation

8. work registration and record.

The role of school principals, among other things, is determined by the functions and areas of work that need to be covered, the competences he must have, the training he needs to achieve the appropriate competences and professional orientation of the staff's efforts, to the responsibilities for the resources.

Given that this is a non-profit organization with a unique goal and function, the school should also be seen as a specific unit, in which general but also specific organizational rules apply. In this regard Staničić (2011) lists two basic functions of the school: administrative-technical and developmental-pedagogical. Administrative and technical tasks are in the function of optimal functioning of the school, which, unlike other organizations, achieves educational work. These include monitoring and enforcement of laws and regulations, regulating the status of employees, adopting internal behavioral procedures, personnel issues, health care, administrative work with students, financial business - cost planning, determining sources and obtaining funds, preparation of financial operations reports, tracking spending, purchase of equipment, payment of salaries, etc. 
The professional and pedagogical field is connected with the main feature of the school as a specific organization. In relation to the administrative and technical, it is much more complex and a more direct involvement of the principal is expected. It includes developmental and pedagogical work related to: planning and programming, organizing, introducing innovations, monitoring and improving teaching, working with children with disabilities, professional orientation, professional development, analysis of the educational results of the school, etc..

Staničić (2011) states that for most schools the ratio of administrative and technical engagement in relation to the developmental and pedagogical is 80:20, and should be reversed. A significant improvement would be their equalization. According to Staničić, this can be achieved by turning the school principal into a pedagogical leader.

Leithwood, Day, Sammons, Harris and Hopkins (2006) cite four main tasks - areas of principal's activity: setting goals, professional development, organizing school and organizing teaching.

McKeever (2003) also speaks of four areas of activity of school principals: work tasks (for their implementation, it is necessary to encourage the development of cooperative relations and positive pedagogical climate, in order to achieve student progress), team building (for coordinators of the activities that teachers will conduct in groups, the principals choose dedicated individuals and encourage the strengthening of cooperation through task allocation), the development of leadership (the principals encourage the distribution of leadership activities to team leaders, but also demonstrate their own commitment - the distribution of leadership activities is not their escape from obligations), ensuring lasting support for the work.

The leadership role of school principals, Blazevic (2004) as well defines the following areas of activity: motivation, communication, interpersonal relations, school development, introduction of innovations and changes, professional development of school employees, and the reputation of the school in society.

The concept of leading an educational institution that was created under the influence of corporate management Kovac, Ledić and Rafajac (2002) designate as managerialism. It is characteristic that decision-making power is concentrated in individuals and / or small groups of people at the top. This concept is based on the assumption that it should be reacted quickly and without redundant consultation, in order to improve the position of the institution in a new, competitive environ- ment. In contrast to managerialism, there is traditional collegialism in leadership. It implies the involvement of all teachers in the institution in decision-making processes through representatives in figures such as councils and commissions. Although it is a concept of leadership in higher education, which is by the level of autonomy and organizational structure different from elementary schools, elements of both practices can be seen in elementary education.

Referring to the OECD (Organization for Economic Co-Opeartion and Development) annual analysis of educational parameters in 2007 (OECD, 2007b) and achievement analysis on PISA Testing in 2006 (OECD, 2007a), Pont, Nusche and Moorman (2008) point to the indirect responsibility of school principals for the improvement of educational outcomes. In order to achieve optimum results, principals need to conceive their leadership in four tasks:

1. ensure conditions and support for professional development of teachers, and their evaluation; 2. setting goals, assessment and responsibility; 3. management of financial and human resources; 4. creating conditions for improving school practice.

From all of the above mentioned, it is clear that the role of principals in the elementary school is complex and multi-dimensional. As leaders, the principals are at the place of an intermediary between the (educational) authorities, represented partly through the school committee, and the teachers, or indirectly, the pupils. The principal is responsible for creating material-technical and personnel conditions for the work of the school, creating a vision and mission of the school and its advancement.

\section{Leadership style}

Leadership style is a relatively durable/persistent way of behaving of the leader who affects employees and the work process in a particular organization. Most of the definitions of leadership are determined by the role of the leader. „The leader is the person who takes responsibility to influence others through interpersonal behavior."(Luft, 1969 according to Bojanović, 2004, p. 156)

The theoretical framework in this paper is the three leadership styles described by Avolio and Bass (2010): transformational, transactional and Laissez-faire leadership. Most Bass (Bass and Reggio, 2006), as well as other authors' studies, indicate that leadership style influences work results and performance in achieving group goals. 
In addition to the leadership style, for the outcomes, according to Bojanović (2004), are responsible situation in which the employees are located, the nature of the tasks at which they work, and the personality traits of employees. Based on these three factors in practice, the most appropriate leadership style for a particular work organization is determined.

In this paper, the leadership styles of elementary school principals are the subject of research in the context of the school climate. Perceived school climate, therefore, counting that the work tasks are constant, will be taken as an indicator of the appropriateness of the existing leadership style, and by comparative analysis, it will be possible to point to the most productive style.

Transformational leadership, according to Avolio and Bass (2002), leads to changes within individuals and social systems. It raises the level of motivation among employees, morally shapes them and increases their performance. This is accomplished through the following mechanisms: creating a common identity between the members of the group and the group as a whole; the leader is a model for identifying to employees; the leader understands the needs, strengths and weaknesses of the employees, and gives them tasks that are in line with it.

Burns (1978) was the first to speak about the leadership style that changes / transforms employees. He called it transformational leadership. According to his definition, transformational leadership is a process in which the leader and employees help one another to achieve a higher level of motivation and morality (Burns, 1978). In contrast to the transformational, Burns defined the transactional leadership, which is based on the mechanism "give and take", more precisely on the exchange mechanism. Transformational and transactional leadership, according to Burns, are mutually exclusive.

Avolio and Bass (2002) expanded Burns theory, replaced the term transforming with transformational, and pointed to the possibility of its measurement. Elements of transformational leadership, according to Avoliu and Bass, are measurable by the influence that the leader realizes on employees. On the other hand, the employees feel the admiration, loyalty and respect towards the leader, and because of the quality shown by the leader, they are prepared to invest more effort and achieve better results. Transformational leader encourages employees to present their own ideas and find their own ways to solve problems. Transformational leadership is observed when the leader: 1 . encourages colleagues and employees to look at work assignments from a different perspective; 2 . encourages the crea- tion of awareness of the importance and significance of the group; 3. encourages colleagues and employees to develop skills and abilities at a higher level; 4. encourages employees and colleagues to rise above their own interests and look at the interests of the group (Bass \& Riggio, 2006).

Transformational leadership according to Bass (1990) is characterized by:

1. individualized care (refers to the attention given by the leader to the employee and his understanding of the employee's needs), 2. intellectual stimulation (the degree to which the leader accepts the ideas of employees and encourages their creative thinking); inspirational motivation (the ability of the leader to articulate goals and gaining employees for their accomplishment), 4. model of identification (the degree to which a leader represents a moral ideal for an employee, receives his respect and trust).

Leithwood and Jantzi (1999) cite the following dimensions of transformational leadership in school as an organization: 1. a high level of performance expectation, 2. building the vision and goals of the school, 3. intellectual stimulation, 4. individualized support, 5. symbolization of professional action and value and 6 . development of structures for participation in decisionmaking on school issues.

Transformational leadership, if we draw a parallel to the classical division into three types of leadership, would correspond to democratic leadership. Viewed through the prism of other theoretical approaches, transformational leadership can recognize the characteristics of people-centered leadership, participative leadership and integrative leadership (Bittel, 1997).

Marks and Printy (2003) suggest that transformational leadership, combined with a distributed instructional, is the most optimal model of school leadership. They call such leadership integrative. In their research, which included directors, teachers and students of the 24 American schools, the authors found that an integrative leadership model gave better results in the quality of teaching and student achievement compared to the dominantly transformational or predominantly instructional model. Marks and Printy emphasize that transformational leadership is a necessary, but insufficient prerequisite for instructional leadership. Thus, they deviate from Leithwood's and Jantzi's (1999) findings, according to which the mixing of leadership and teaching process leads to dissatisfaction of both leaders and teachers. They conclude that the integrative model represents the synergistic power of leadership, shared by members of the school organization. 
Transactional leadership is based on the principle giveand-take. In this case, the leader gives the employees guidelines, acknowledgments and a system of values, and in turn he takes / receives respect and obedience. Transactional leadership is most obvious in cases where the leader relies on passive leadership mechanisms, i. e. he only intervenes when the work procedure is violated or the target has not been achieved. $\mathrm{He}$ then threatens or punishes (Bass, 1990). According to Burns (1978), transactional leadership is the most common style, but also a style that does not provide either a leader or an employee with a high level of motivation and intellectual stimulation.

Transactional leadership is recognized in autocratic leadership, task-oriented leadership, direct and dominant leadership (Bittel, 1997).

Laissez-faire leadership style, as described by Lewin, Lippitt and White (1939), implies a minimum involvement of the leaders. Decisions are made by members of the group, taking responsibility for their outcomes. Some authors describe this style in a negative light, while others perceive how it can deliver excellent results in the case of tasks requiring creativity, when there is no high level of coordination among group members, and when group members have a high level of their own responsibility.

Laissez-faire style of leadership in the literature is also referred as deciding through individual freedoms (liberal leadership). „Decision-making through individual freedoms is based on the maximum freedom of all members of the group in deciding. This style is most often used by groups of scientists, characterized by a high degree of individuality. "(Bojanović, 2004, p. 162)

Avolio and Bass (2010) paid less attention to this style of leadership. In their instrument they described it through only one leading component - passive / avoided leadership. (This is also the other name Avolio and Bass use for this style of leadership.) Perhaps because in most cases where a conscious, deliberate, and planned activity is expected from the leader, this style of leadership has no place. Nevertheless, its presence in practice has been confirmed by a large number of researches, beginning with the earliest ones conducted by Lewin, Lippith and White (1939), pointing out the consequences that can be left for interpersonal relationships within the group, and the work achievement.

Cuadrado, Navas, Molero, Ferrer and Morales (2012) investigated differences in the dominant leadership styles with regard to gender and type of organization of leaders. They have come to the conclusion that both male and female leaders in principle have been equally often self-engaged as transformational, or transactional. Nevertheless, small differences were found with regard to subscales autocratic behavior and negotiation in the perception of leadership style by employees, where male respondents more often evaluated women leaders as prone to autocratic behavior and negotiation. The authors note that these results are contrary to meta-analytical results, which indicate that all employees tend to perceive female leaders as more sensitive to employee needs and interpersonal relationships / more inclined to transactional style of leadership (Eagly et al., 2003; van Engen \& Willemsen, 2004 according to Cuardado et al. 2012).

So far, research has shown that pure leadership styles are almost never encountered in practice. Usually, the leader has elements of two, or even three, styles with the dominance of one. That's why it's mostly talked about the dominant leadership style.

\section{School climate}

The term school climate refers to the invisible dimension of school life, which is the result of the overall relationships of all its employees and students, and each of them experiences subjectively, at the level of one's own emotions, social relations and work environment. It's about climate of the school as a group / organization. For the precise definition of the organizational climate, it is essential, Sušanj (2005) states, to understand her. In this sense, from the earliest studies, two directions are evident: objectivistic or realistic, subjectivist or phenomenological. The first understanding implies that the climate exists objectively, as part of the organization's reality. Although it is composed of typical behaviors, attitudes and feelings, climate is an attribute that exists independently of the perception of members of the organization. Contrary to this, according to subjectivist understanding, the climate refers to the perceptual and cognitive structuring of the organizational situation, common to its members. This implies that the climate does not exist objectively and that it represents the result of personal cognitive maps of all members of the organization, which they perceptively and cognitively structure the organizational situations. Nevertheless, Sušanj (2005) finds in all of these definitions two common features of the organizational climate: perception (experience of the organizational environment) and descriptiveness (these are the personal reports of members of the organization on how they perceive the organizational environment). 
In defining the school climate, Rafferty puts emphasis on the role of principal and teachers in creating it, not mentioning students in particular. „The school climate is an organizational climate in specific school conditions. It encompasses the whole personality principals and teachers - in interaction with the social and psychological environment of each school. “(Rafferty, 2003, p. 52)

Bognar and Matijević (2002) speak of educational climate. The climate is examined at the level of teaching and analyzed through two components: social climate and emotional climate. The social climate considers the quality of the overall relations of participants in the educational process. The emotional climate implies a feeling of comfort and discomfort among the participants in the educational process. In the case of emotional climate, the teacher / leader play a crucial role as well.

Taking into consideration all the above mentioned definitions, the school climate can be understood as a psychosocial climate created in the school as a specific organization, which consists of the behaviors, attitudes and feelings of its principals, teachers, professional associates and students.

This paper examines five dimensions of the school climate, defined by Johnson, Stevens and Zvoch (2007): 1. Collaboration, 2. Decision-making, 3. Instructional innovation, 4. Student relations, 5. School resources. Each dimension is described with three to six particles in the instrument. Dimensions are shown in Table 5 in more detail.

\section{METHODOLOGY OF RESEARCH}

\section{Research objective}

The objective of this paper was to investigate the role of elementary school principals in creating a school climate by critically analyzing, determining and interpreting the relation of the leadership style of principals perceived by teachers and their perceptions of the school climate.

\section{Hypothesis of research}

We have assumed that there is a connection between the observed leadership style of the principals of elementary schools with the experience of the school climate by the teachers.

\section{Sample respondents}

Teachers and principals of elementary schools in the wider city area of Tuzla made up the universe of testing. The sample included 492 respondents - 467 teachers and 25 principals of elementary schools. The sexual distribution of the respondents in the sample is asymmetrical, reflecting the population inequality - 307 (65.7\%) female teachers and 89 (19.1\%) male teachers, while for $71(15.2 \%)$ of the respondents there is no registered gender. In the sub-sample of principals, $19(76 \%)$ are male, and $6(24 \%)$ are female. The age of the subjects ranged from 24 to 64 years $(M=43.12 ; M d n=43 ; \sigma=9.15 ; S k=0.18 ; K=-$ 0.55). Differences in age of teaching staff were not revealed $(\mathrm{MF}=43.10 ; \mathrm{MM}=43.01 ; \mathrm{t}=0.07 ; \mathrm{df}=370$; $\mathrm{p}=0.937 ; \mathrm{FL}=2.23 ; \mathrm{pL}=0.136)$, As well as in length of service $(\mathrm{MF}=17.78 ; \mathrm{MM}=17.11 ; \mathrm{t}=0.55 ; \mathrm{df}=370$; $\mathrm{p}=0.578 ; \mathrm{FL}=0.54 ; \mathrm{pL}=0.462)$. The average chronological age of principals is marginally different from the age of the teaching staff $(\mathrm{M}=44.88 ; \mathrm{Mdn}=42)$ and the length of service $(M=20.83$; $M d n=20)$. Differences in the age and length of service of male and female principals are not statistically significant (age: $\mathrm{MF}=45.80 ; \mathrm{MM}=44.63 ; \mathrm{t}=0.24 ; \mathrm{df}=22 ; \mathrm{p}=0.808$; $\mathrm{FL}=1.19 ; \mathrm{pL}=0.287$ ); (lenght of service: $\mathrm{MF}=22.40$; $\mathrm{MM}=20.42 ; \quad \mathrm{t}=0.42 ; \quad \mathrm{df}=22 ; \mathrm{p}=0.681 ; \quad \mathrm{FL}=1.54$; $\mathrm{pL}=0.228$ ). One respondent among the principals did not provide information on sexual affiliation.

\section{Research methods, techniques of data collection and processing}

In this research analytical - descriptive method, method of theoretical analysis and survey methods, and surveying and scaling techniques, as well as compiling and statistical data processing were applied.

The analytical - descriptive method provides a deeper insight into the nature of what we are doing with, and an explanation of the problem being investigated. In the case of this research, the analytical - descriptive method and the method of theoretical analysis were used to show the most important theoretical considerations and empirical contributions, leadership styles of elementary school principals, and the characteristics of the school climate.

The Survey method is an empirical non-experimental method, whose main characteristic is to address subjects to give opinions or statements about themselves. It is suitable for examining attitudes, opinions, views and knowledge about a problem. 
We used it for the purpose of gathering the data needed to respond to the set objective and research tasks related to the leadership styles of elementary school principals and the characteristics of the school climate.

A computational program will be used for compiling and statistical data processing, which will, with the application of appropriate procedures of descriptive and inferential statistics, analyze the results of the research. Depending on the distribution of the results obtained,the program will determine their validity, reliability and correlation between variables.

Among the "standard" statistical procedures, in addition to descriptive statistics, multiple regression (OLS) was used, as well as a direct quadratic discriminative analysis that was robust in the heterogeneity of covariates, and was assumed by several authors in relation to linear discriminatory analysis in conditions where the assumptions related to covariance variables (Smithson, 1947; McLachlan, 2004). The discriminative model was implemented in the R environment using the "MASS" package. Graphic solutions are also created in the $\mathrm{R}$ environment in the package "CAR".

\section{Research instrument}

The research used the Multifactor Leadership Questionnaire (MLQ), authored by Avolio and Bass, and the abbreviated version of the School Level Environment Questionnaire (SLEQ), by Johnson, Stevens, Zvocha (authors of the original version of the instrument are Rentoul and Fraser).

Multifactor Leadership Questionnaire (MLQ) is used for the study of the transformational, transactional, and Laissez-faire (passive / avoiding) leadership style. It consists of 45 particles that identify and measure key leadership behaviors that have been shown to be strongly linked to individual and organizational success in previous researches. A scale of five degrees is used to estimate the frequency of observed behaviors. Nine leadership components are measured along the entire range of leadership styles and three leadership outcomes. The five components describe the transformation; the four components are transactional, while the Laissez-faire leadership is described through one component. In order to evaluate the validity of the measurement model of the leadership questionnaire, the author's hypothesis was examined on the structure of the scale itself. A complete confirmation model was tested with the inclusion of 11 latent dimensions and 45 indicators. Since it was not possible to obtain a convergent solution, the original model was corrected. Subscale Ideal- ized impact had one item removed (mlq 6: "Speaking of its most important values and beliefs"), and the passive leadership subscale, consisting of 4 items (mlq3, mlq12, mlq17 and mlq20) was removed entirety. The corrected model has an acceptable level of fit $(\mathrm{c} 2(730)=2709.04$, $\mathrm{p}<0.001 ; \quad \mathrm{SRMR}=0.073, \mathrm{RMSEA}=0.075, \mathrm{CFI}=0.98$, TLI=0.98). General fit indices (SRMR and RMSEA) indicate a relatively low degree of matching with the assumed structure of the questionnaire, while on the other hand comparative fit indices (TLI and CFI) show a significantly better degree of matching.

The School Level Enviroment Questionnaire (SLEQ) is used to assess the school climate. The original version consists of 56, and the abbreviated, used in this research, of the 21 claims that teachers are exposed to on a seven-hour scale. Each claim belongs to one of the five sub-scales, which describe five dimensions of the school climate. These are Instructional Innovation, Collaboration, Decision-Making, School Resources and Student Relations. The paper replicated the model Johson and associates confirmed in the last "big" revision of the instrument ten years ago (Johson, Stevens $\&$ Zvoch, 2007). The results showed that both general and comparative indices point to a scale with modest factor validity $\left(\chi^{2}(179)=717.08 ; \mathrm{SRMR}=0.074\right.$, RM$\mathrm{SEA}=0.087, \mathrm{CFI}=0.90$, TLI $=0.89$ ). An additional difficulty was the need to incorporate assumptions about covariates into the model among the factors that the authors of the scale did not have to test. As all the initial estimates indicated that the decision-making factor was particularly problematic, a model with four factors was tested, i.e. a model without the factor decision-making, with 18 items included. A significantly more convergent model was obtained $\left(\chi^{2}(129)=465.43, p<0.001\right.$; $\mathrm{SRMR}=0.056, \mathrm{RMSEA}=0.058, \mathrm{CFI}=0.92, \mathrm{TLI}=0.91)$. Most indices are "at the very edge" of the model with a good fit.

\section{Data analysis}

Based on the standard regression analysis (OLS), the magnitude of the contribution of the perceived leadership style of principals on the teacher's experience of pedagogical climate was evaluated. The predicate set of variables consists of eight factors of the leadership scale that relate to the transformational, transactional and Laissez-faire leadership style (Idealized Attributed Impact (IA), Idealized Behavior Impact (IB), Inspirational Motivation (IM), Intellectual Stimulation (IS), Individualized Care (IC), Conditional Reward (CR), Active Management (AM)). 
The last two dimensions feature the transactional style of leadership, and the Laissez-faire (LFR) leadership style is presented through a unique dimension composed of four items. Criterion variables make up four dimensions of the questionnaire of the school environment - climate: Instructional Innovation, Collaboration, Resources, Student Relations. A separate regression model is created for each criterion variable.

All variables in the regression model are decomposed onto the first main component, and the factor scores are expressed in the form of regression scores. Based on the correlation matrix for the set of included variables in the regression model it has been established that all predictor variables statistically significantly correlate with the dimensions of the perceived school climate. Although the registered correlations are statistically significant, it should be emphasized that the magnitude of the association is relatively modest. Thus Instructional Innovation poorly to moderately correlate with the set of MLQ variables (0.40 - 0.48), Collaboration correlates

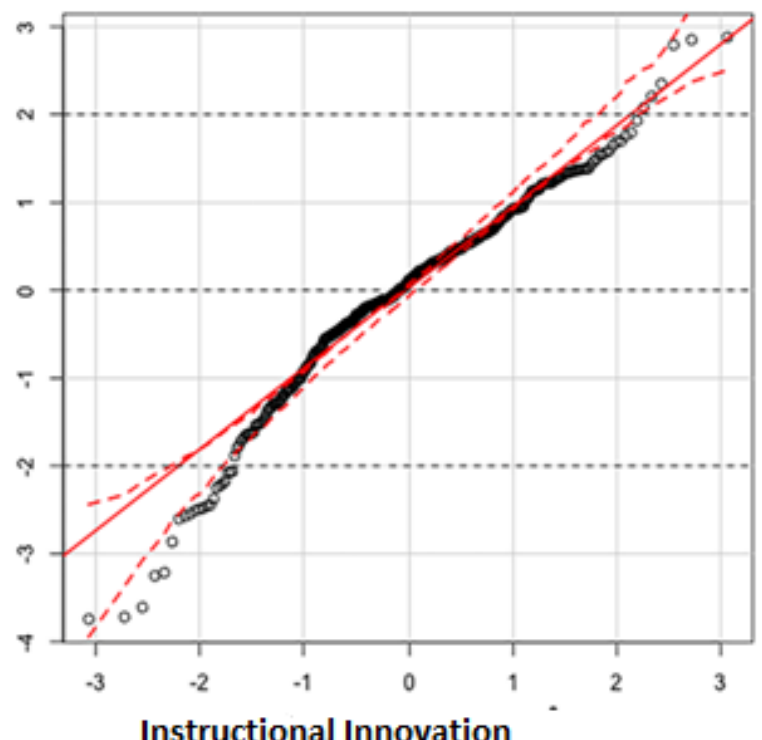

Instructional Innovation

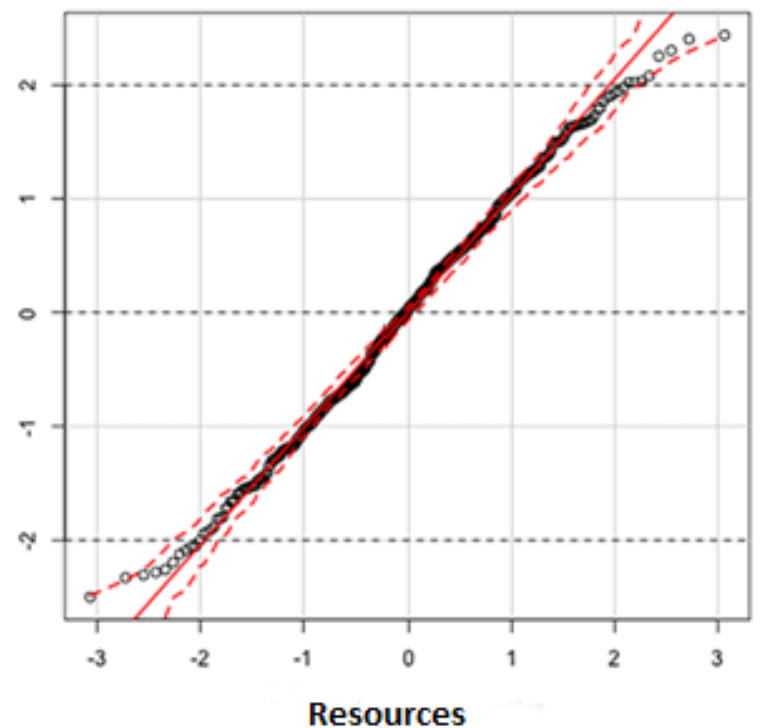

relatively low $(0.26-0.43)$. The same is true with the variable Resources that has a modest association with a set of variables that represent perceived leadership styles (0.21-0.35), and especially interesting is the very low association of the dimension Teacher Relations with a set of predictors whose correlations do not exceed the order of 0.10 . This could point to a paradox that relationships with students are independent of the teacher's perception of leadership.

All variables that represent leadership styles statistically correlate significantly with each other. Although there are conditions for violating the criteria of multicollinearity, recommendation of the leading authors to include all the variables in the regression model that do not share more than half of the common variance was followed (Tabachnik \& Fidell, 2012).

Data consistency in relation to the normal distribution density model, as well as the assumption of the normal distribution of residuals, is plotted graphically on a diagram of the normal likelihood of the residual (Picture 1).
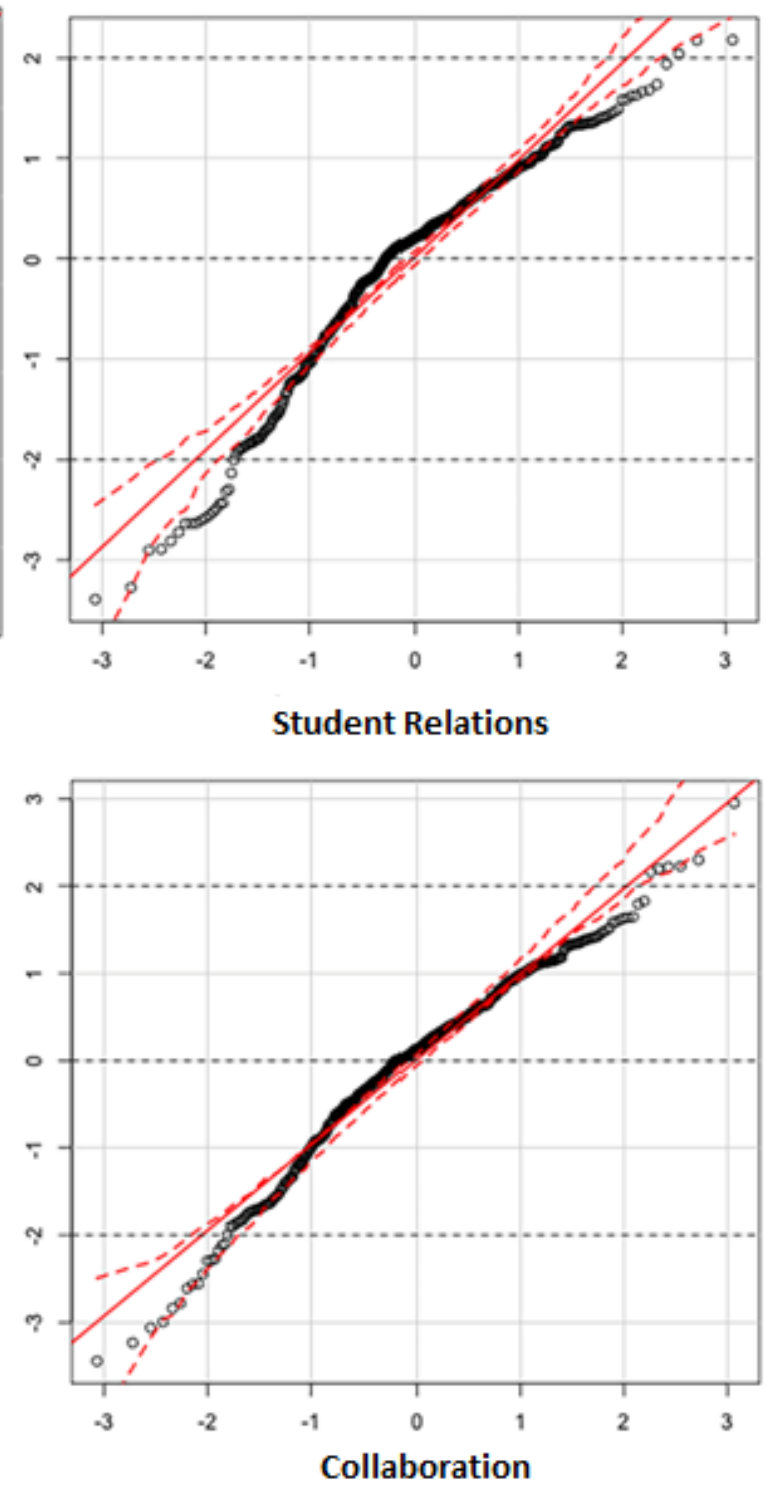

Picture 1. "Integral" graphic representation of the probability of normal distribution of residuals on criterion variables from the SLEQ set-teachers' experience of the pedagogical climate 
All four distribution residues do not indicate significant deviations from the normal distribution model of residuals, and there is no fear of breaking the prerequisites for regression analysis.

Since subscales during the psychometric evaluation have been somewhat corrected (some items have been deleted), the descriptive indicators for the predictor and criterion variables (Table 1) were derived under simple summation models and under the model of average scaled values to facilitate comparison of results in regard to earlier research. The averaging and deviation measures for factor scores are not shown because they are expressed through standard regression scores $(\mathrm{M}=0 ; \sigma=1)$.

Table 1 Average values and standard deviations for the subscales of the questionnaires MLQ and SLEQ

\begin{tabular}{lcccc}
\hline & \multicolumn{2}{c}{$\mathbf{M}$} & & \multicolumn{2}{c}{$\mathbf{~}$} & $\mathbf{j s v}$ \\
\cline { 2 - 5 } subscales & $\mathbf{j l k}$ & $\mathbf{j s v}$ & 4.10 & 1.02 \\
\hline Idealized Attributed Impact & 10.77 & 2.69 & 3.07 & 0.81 \\
Idealized Behavior Impact & 9.01 & 2.73 & 3.97 & 0.99 \\
Inspirational Motivation & 11.99 & 2.99 & 3.90 & 0.97 \\
Intellectual Stimulation & 11.40 & 2.85 & 4.02 & 1.05 \\
Individualized Care & 11.92 & 2.98 & 4.01 & 1.00 \\
Conditional Reward & 11.31 & 2.82 & 3.64 & 0.91 \\
Active Management & 11.38 & 2.84 & 4.22 & 1.05 \\
Laissez-faire style & 4.06 & 1.01 & 2.88 & 0.72 \\
Instructional Innovation & 14.64 & 3.66 & 3.57 & 0.71 \\
Collaboration & 19.41 & 3.80 & 3.63 & 0.90 \\
Resources & 11.20 & 2.80 & 3.20 & 0.80 \\
Student Relations & 15.09 & 3.77 & & \\
\hline
\end{tabular}

Note. M-arithmetic mean; $\sigma$-standard deviation; jlk-summatic score created as a simple summation; psv-average scalar value

Taking the theoretical scale of scoring on sub-scales, it can be established that all scales have a relatively moderate and uniform scattering level. To a lesser extent of this trend deviates from the subscales of Idealized Attributed Impact, which compared to other scales in the model and has a somewhat higher degree of fluctuation in the results. The highest average values on the pedagogical climate experience scale are registered on subscales: Collaboration $(\mathrm{M}=3.80)$, Student Relations $(\mathrm{M}=3.77)$ i Instructional Innovation $(\mathrm{M}=3.66)$, While on the scale of perceived leadership the highest scores are registered on the subscales: Inspirational Motivation ( $\mathrm{M}=2.99)$; Individualized Care $(\mathrm{M}=2.98)$ i Intellectual Stimulation $(\mathrm{M}=2.85)$. Since the maximum theoretical average scalar value of both scales 4 , it is obvious that the scales separated have an above average value. The lowest scores on the leadership scales are registered with Laissez-faire leadership style $(\mathrm{M}=1.01)$, and on the subscale Idealized
Attributed Impact $(\mathrm{M}=2.69)$. As was expected and "the modest" was the perceived pedagogical climate that is tied to the material equipment of the school (Resources $\mathrm{M}=2.80$ ).

Since high correlations were found in a set of prediction variables (order 0.60 and 0.70), special care is devoted to the diagnosis of colinearnity. In accordance with the recommendations of leading authors in the field (Myers, 1990; Menard, 1995; Tabachnick and Fidell, 2012), a regression model with tolerance coefficient values of less than 0.20 and values of the factor of increase of the explained variance greater than 10 can be considered unreliable due to high intercorrelation of the predictor variables. Since neither of the four regression models have registered any significant cases of disruption of the multicollinearity conditions, the obtained models can be treated as reliable. A detailed overview of the collinearity diagnosis is presented in Table 2 . 
Table 2 Multicollinear Diagnostics: Tolerance coefficients and variance increase factors for regression models of the assessment of the aspect of the pedagogical climate

Prediction variables

\begin{tabular}{lcccccccr}
\hline & $\boldsymbol{I}$ & $\boldsymbol{I B}$ & $\boldsymbol{I M}$ & $\boldsymbol{I S}$ & $\boldsymbol{I C}$ & $\boldsymbol{C R}$ & $\boldsymbol{A M}$ & $\boldsymbol{L F R}$ \\
Tolerance & 0.264 & 0.119 & 0.148 & 0.133 & 0.107 & 0.189 & 0.235 & 0.577 \\
VIF & 3.788 & 8.406 & 6.776 & 7.494 & 9.339 & 5.299 & 4.250 & 1.732 \\
\hline
\end{tabular}

Note. IA- Idealized Attributed Impact; IB- Idealized Behavior Impact;IM- Inspirational Motivation;IS- Intelectual stimulation; IC- Individualized Care; CR-Conditional Reward; AM- Active Management; LFR - Laissez-faire leadership style

The basic question regarding the relation of leadership dimensions registered over the MLQ questionnaire scale and the perception of the pedagogical climate estimated through the SLEQ questionnaire is how well knowledge of information on leadership styles contributes to the possibility of forecasting the level of pedagogical climate. In order to answer the question, four successive models were created with the simultaneous use of the predictor variables. Since the average correlation (Instructional Innovation $r^{-}=0.43$, Collaboration $r^{-}=0.36$, Student Relations $r$ $=0.13$ i Resources $r^{-}=0.31$ ) of predictor variables with a criterion is relatively low, and two sets of variables have a modest amount of common variance, so the expected predictive potentials of the model are limited. A detailed overview of the general efficiency of the model is shown in Table 3.

Table 3 General indicators of efficiency of regression models:Coefficients of multiple correlation and multiple determination

\begin{tabular}{lcccc}
\hline Model & $\boldsymbol{R}$ & $\boldsymbol{R}^{2}$ & $\boldsymbol{\Delta R}^{2}$ & Standard error \\
\hline 1 Instructional innovation & 0.50 & 0.27 & 0.24 & 0.87 \\
2 Collaboration & 0.45 & 0.21 & 0.19 & 0.92 \\
3 Resources & 0.37 & 0.14 & 0.12 & 0.93 \\
4 Student relations & 0.18 & 0.03 & 0.02 & 0.98 \\
\hline
\end{tabular}

Note. $\mathrm{R}$ - coefficient of multiple correlation; $\mathrm{R}^{2}$ - coefficient of multiple determination; $\Delta \mathrm{R}^{2}$ - corrected $\mathrm{R}^{2}$

The most effective model was the regression solution for the prediction scores model on the Instructional Innovation dimension, where about $24 \%$ of the variance of the perception of the school climate which refers to the aspect of Instructional Innovation was explained $\left(\mathrm{R}=0.50 ; \mathrm{R}^{2}=0.24,95 \%\right.$ IP from 0.16 to 0.30 ; Cohens $\left.\mathrm{f}^{2}=0.31, \mathrm{p}<0.001\right)$. The regression model that addresses the issue of Collaboration prediction as a school climate aspect is less useful than the previous model $\left(\mathrm{R}=0.45 ; \mathrm{R}^{2}=0.19,95 \%\right.$ IP from 0.11 to 0.24 ; Cohens $\mathrm{f}^{2}=0.23, \mathrm{p}<0.001$ ), and about $1 / 5$ of the variance of the school climate was explained. A regression model that challenges the climate prediction from the point of view of the Resources $(\mathrm{R}=0.37$; $\mathrm{R}^{2}=0.12,95 \%$ IP from 0.05 to 0.15 ; Cohens $\mathrm{f}^{2}=0.13$, $\mathrm{p}<0.001$ ), about $12 \%$ of the school climate variation is explained. The least useful regression solution in the prediction of the school climate was the aspect of Student Relations. Although the model is statistically significant in practical terms, the model is extremely marginal $\left(\mathrm{R}=0.18 ; \mathrm{R}^{2}=0.02,95 \%\right.$ IP from 0.00 to 0.03; Cohens $\left.\mathrm{f}^{2}=0.02, \mathrm{p}<0.001\right)$. The model explains only about $2 \%$ of the school climate variation related to student relations. According to the Cohen's convention interpretations $\mathrm{f}^{2}$ as a measure of magnitude of the effect in multiple regression of $\mathrm{f}^{2}$ values from 0.02 to 0.14 indicate a small effect, at a moderate effect of values from 0.15 to 0.35 , and to a large effect of a value greater than 0.35 . 
Accordingly moderate effects have models Instructional Innovation and Collaboration, while models for School resources and Student Relations have a small effect.
The summarized results of variance analysis with the most relevant information for all four tested models are shown in Table 4.

Table 4 Summary indicators of variance analysis for the tested regression models

\begin{tabular}{|c|c|c|c|c|c|c|}
\hline Model & & SS & df & MS & $\mathbf{F}$ & $\mathbf{p}$ \\
\hline \multirow{3}{*}{ Instructional Innovation } & Regression & 117.34 & 8 & 14.66 & 19.26 & 0.001 \\
\hline & Residual & 348.65 & 458 & 0.76 & & \\
\hline & ukupno & 466.00 & 466 & & & \\
\hline \multirow{3}{*}{ Collaboration } & Regression & 96.69 & 8 & 12.08 & 14.98 & 0.001 \\
\hline & Residual & 369.30 & 458 & 0.81 & & \\
\hline & Total & 466.000 & 466 & & & \\
\hline \multirow{3}{*}{ Resources } & Regression & 63.82 & 8 & 7.97 & 9.08 & 0.001 \\
\hline & Residual & 402.17 & 458 & 0.87 & & \\
\hline & Total & 466.000 & 466 & & & \\
\hline \multirow{3}{*}{ Student Relations } & Regression & 16.22 & 8 & 2.02 & 2.06 & 0.03 \\
\hline & Residual & 449.77 & 458 & 0.982 & & \\
\hline & Total & 466.00 & 466 & & & \\
\hline
\end{tabular}

Note. SS- sums of squares; df- degrees of freedom;MS-average square F-Fisher's F ratio

Partial i.e. the individual contribution of variables to the regression model is estimated through standardized regression coefficients $\beta$. To the first regression model (Instructional Innovation) significantly contribute only two variables Idealized Attributed Impact -Behavior $(\beta=0.24, t=2.06, p<0.05)$ and the variable Laissez-faire leadership $(\beta=-0.11, \mathrm{t}=2.25, \mathrm{p}<0.05)$. The same predictors also contribute significantly to the explanation of the second regression model Collaboration: Idealized Attributed Impact - Behavior $(\beta=0.27, t=2.25, \mathrm{p}<0.05)$; i Laissez-faire leadership $(\beta=-0.29, \mathrm{t}=5.24, \mathrm{p}<0.05)$, while the individual contribution of the remaining variables is trivial. The third regression model did not result in any single statistically significant predictor, and this is particularly true for the fourth model. Due to the extremely modest partial contribution of the predictor, only a reduced table with significant regression coefficients for the first two models was included. The complete printing of tables with regression coefficients for all four models is found in Table 5. 
Table 5 Partial contribution of predictor variables from the set perceptible leadership style to the forecast of the pedagogical climate by teachers

\begin{tabular}{|c|c|c|c|c|c|c|c|}
\hline Model & & B & $\begin{array}{l}\text { Std. } \\
\text { Error }\end{array}$ & $\boldsymbol{\beta}$ & $s r^{2}$ & $\mathbf{t}$ & $\mathbf{p}$ \\
\hline & Constant & $6.380 \mathrm{E}-17$ & 0.040 & & & 0.000 & 1.000 \\
\hline & Idealized Impact - & 0.242 & 0.117 & 0.242 & $>0.01$ & 2.065 & 0.040 \\
\hline \multirow{6}{*}{$\begin{array}{l}\text { Instructional } \\
\text { Innovation }\end{array}$} & Behavior & & & & & & \\
\hline & & & & & & & \\
\hline & Laissez-faire & -0.114 & 0.053 & -0.114 & $>0.01$ & -2.140 & 0.033 \\
\hline & leadership & & & & & & \\
\hline & Constant & $1.827 \mathrm{E}-17$ & 0.042 & & & 0.000 & 1.000 \\
\hline & Idealized Impact & 0.272 & 0.121 & 0.272 & $>0.01$ & 2.253 & 0.025 \\
\hline \multirow[t]{3}{*}{ Collaboration } & -Behavior & & & & & & \\
\hline & Laissez-faire & -0.287 & 0.055 & -0.287 & 0.04 & -5.245 & 0.000 \\
\hline & leadership & & & & & & \\
\hline
\end{tabular}

Note.B - Non-standardized regression coefficient; $\beta$ - standardized beta coefficient; sr2-square coefficient of semi-partial correlation; $t$ - Student's t test.

It should be emphasized that, although the regression coefficients are statistically significant, their magnitudes are not remarkable. However, it should be kept in mind that leadership styles are a relatively small and homogeneous set of predictors, and therefore their impact is relatively modest. The direction of the forecast agrees with the assumed model: a more favorable perception of idealized behavioral effects leads to a more favorable experience of the school climate in aspects Instructional Innovation and Collaboration. The opposite is by the predictor of the Laissez-faire leadership, where the perception of the multiple presence of the Laissez-faire style of leadership is more in line with less favorable perceptions Instructional Innovation and Collaboration.

Based on the results of a multiple regression analysis carried out on 8 predicate variables from the leadership style, representing the experienced leadership style of the principals, and the dimension of the SLEQ scale that presents the school climate as dependent variables, using a regression model with the simultaneous inclusion of the predictor, four statistically significant regression functions stand out. The obtained models explain from 2 to $24 \%$ of the variance of perceived school climate through the MLQ leadership dimension. The most useful was the predictor's solution for the criterion Instructional Innovation, and the least suitable was the prediction Student Relations, which turned out to be completely independent of the style of leadership. The partial contribution of the predictor in all the solutions is negligible and in no case does it exceed the increment of $5 \%$ variance.

\section{DISCUSSION}

As pointed out above, the purpose of this paper was to investigate the perceived leadership style of the principals and the teachers' experience of the school climate in elementary school, in total and in each dimension of the individual climate. From this formulated task, the assumption is that there is a connection between the leadership style of the principal and the experience of the school climate by teachers, that is, that the statistically and practically significant part of the climate experience variance, in total and in every dimension, can be explained by the style of leadership. Also, it is assumed that teachers, which will mostly perceive the principals as transformational, will also perceive the school climate as more favorable. 
By analyzing the obtained data, the research hypothesis has been largely confirmed. The coefficient of multiple correlation between the seven dimensions of leadership style, on the one hand, and the four dimensions of the school climate, on the other hand, ranges from 0.18 to $0.50^{2}$ (i.e. The corrected determination coefficient ranges from 0.02 to $0.24^{3}$ ), and in the case of three out of a total of four models, it indicates an association. In other words, up to $24 \%$ of the variance of the climate experience of teachers can be explained by the style of leadership the teachers see. Taking into account the obtained predictor value of the variables, the preferred leadership style is the transformational.

The strongest link was found between the style of leadership of principals, as perceived by teachers, and Instructional Innovation as the dimensions of the climate experience. $\mathrm{R}=0.50\left(\mathrm{R}^{2}=0.24\right)$ is located on the upper boundary weak to moderate to good association. Although Instructional Innovations are in correlation with the leadership style of principals in general, only the dimensions Idealized Impact - behavior and variables Laissez-faire (the sign in the case of Laissez-faire leadership is negative) have a predictor value in this relation. As the Idealized Impact - Behavior is a dimension that describes the transformational style of leadership, it can be concluded that teachers who largely school principals perceive as transformational leaders - who speak of their most important values and beliefs, clarify the importance of owning a strong sense of meaning and purpose, take care about the moral and ethical consequences of decisions, and emphasize the importance of having common goals, be more inclined to try new and different ideas, more often introduce new contents into curricula (within the limits where teachers allow it), prefer to apply new approaches to teaching work, and will be more inclined to evaluate their colleagues and themselves as innovative.

\footnotetext{
${ }^{2}$ The boundary values for the coefficient of correlation are the following: $0- \pm 0.25$ - no association; $\pm 0.26- \pm 0.50-$ poor association; $\pm 0.51- \pm 0.75$ - moderate to good association; \pm 0.76 - \pm 1 very good to great association; \pm 1 - mathematical association.

${ }^{3}$ The boundary values for the coefficient of correlation are the following (Chadock's scale): 0 - absence of link; 0,00 - 0,25 weak link; 0.25 - 0.64 - medium-power link; $0.64-1$ - strong link; 1 - complete link
}

Since the Idealized Impact is a dimension of the transformational leadership, we can conclude that this style is preferred in the case of introducing teacherbased innovation in teaching in relation to the other two styles; especially in relation to the Laissez-faire style of leadership. Namely, given the negative sign in relation to Instructional Innovation - Laissez-faire leadership, we conclude that teachers who largely perceive their principals who avoid to include when important questions arise, that they are absent when they are most needed, to avoid making decisions, and to postpone answering urgent questions, be inclined to evaluate the teaching work of their colleagues as less innovative.

Although statistically significant, and on the edge of a moderate to good association, such a result can be rendered unsatisfactory. In other words, it can be done how the principal's role in teacher innovation is below expectations. Before accepting such a conclusion, however, it is necessary to take into account that the issue of introducing innovations in teaching is complex, and that it depends not only on a multitude of potential factors within the school, of which the principal is only one, but also from those from outside. It is therefore possible to assume that with $24 \%$ variance, the principal in any case represents one of the most important factors of innovation in teaching. However, in order to make a firm conclusion on this trail, it would be necessary to carry out a comprehensive factorial analysis on the same or similar sample. Nachmias, Mioduser, Cohen, Tubin and Forkosh Baruch (2004) pointed out to the number of factors that influence innovation. In a survey conducted in Israeli schools, the principal (together with the leading staff in charge of technical support and leading teachers) is the second most important factor in the implementation of pedagogical innovations related to computer technology (with a weight of 3.8), immediately after the information infrastructure (4.1), and before past practices in introducing innovations (3.7), state and local information policies (3.6), professional teacher training (3.4), "significant external" factors, including the Ministry of Education, local authorities, parents, sectorial experts and "intervening" factors common weight 3.0) and the number of classes and student structure (common weight 1.8). This issue will be discussed below, in the context of a common interpretation of the link between the dimensions of the climate with the style of leadership. 
Interestingly, the Idealized Impact (Attributed) and Idealized Impact (Behavior) have been shown to be the only predictor variables in relation to the school climate and in the research conducted by Allen, Grigsby, and Peters (2015). Both idealized impacts, in addition to the predictor value, have shown a relatively high relation to all seven dimensions of the school climate: order, leadership, environment, inclusiveness, teaching, expectations and cooperation, with an explanation of variance from $16 \%$ to as much as $62 \%$.

At almost the same association (obtained in our research) between the observed transformational style of school principals (MLQ) and Instructional Innovation (SLEQ) as the dimensions of the school climate $(\mathrm{R} 2=0.26)$, point out Tajasom and Ahmad (2011). Their results are based on a sample of 170 teachers from 17 Malaysian high schools. On the other hand, the same research found the link between the transaction style of leadership and Instructional Innovation, for which the determining factor is $\mathrm{R}^{2}=0.21$.

The second strongest link of the perceived leadership style of the principal was achieved with the subscale of Mutual Teacher Collaboration. The correlation factor of $\mathrm{R}=0.45$ in this case as well indicates a weak association of the dependent variable with an independent while the determining factor $\mathrm{R} 2=0.19$ suggests that $19 \%$ of the variance of the mutual teacher collaboration can be explained with the leadership style of the principal. Like Instructive Innovation, the Idealized Impact-Behavior and Laissez-faire style (which is negative again) proved to be significant predictors of Collaboration. This means that teachers who are more likely to notice that their principals are talking about their most important values and beliefs, clarify the importance of owning a strong sense of purpose and purpose, take into account the moral and ethical consequences of decisions and emphasize the importance of having common goals, more often and more commonly adapt / operationalize curricula, communicate better with each other, collaborate better, talk about the individual needs of students, adjust their work on the choice of teaching content and the dynamics of their realization, and notice the higher level of team work of teachers. Since the idealized impact is a dimension of transformational leadership, we conclude, that based on the perception of teachers, transformational leadership contributes more to the realization of cooperation and development of collaborative relationships among teachers in comparison with transactional and especially Laissez-faire leadership (and thus the preferred style). Namely, due to the negative sign in the relationship of Collaboration - Laissez-faire leadership, we will exclude that teachers who notice their principals avoiding to be involved when important questions arise, that they are absent when they are most needed, to avoid decision making, and postpone answering urgent questions, be inclined to evaluate the work of their colleagues as less cooperative.

Given that the perceived leadership style explains $15 \%$ of the variance of teacher collaboration, it is clear that the role of the principal in creating this dimension of the school climate is lower than in the case of Instructional Innovation in teaching. A possible explanation for this result lies in the fact that relations among teachers are a more dynamic category of innovation, and as such is largely conditioned by teachers themselves, and less by external factors, including the principal.

DuPont (2009) found a stronger relationship $(\mathrm{R}=$ 0.60 ) between the principal's style of leadership and mutual teacher collaboration, in a case study conducted at the International School at the US Embassy in New Delhi. In his research, as much as 35\% of the variance of mutual teacher collaboration was explained by the style of teachers' leadership. A possible reason for a $20 \%$ difference in variance is the fact that DuPont conducted a survey in a school where teachers rated the principals as highly instructive; The arithmetic mean of the response on a scale of 1 to 5 has exceeded 3.5 of each of the nine dimensions of instructive leadership, while in some cases it climbed above 4.1. In support of this interpretation, there are also relatively high variances found in relation to the style of leadership of principals and other dimensions of the school climate, as perceived by teachers: Professional development $\left(\mathrm{R}^{2}=0.27\right)$, Unification in achieving the mission of the school $\left(\mathrm{R}^{2}=0.32\right)$, Collegial support $\left(\mathrm{R}^{2}=0.28\right)$, Partnership in learning $\left(\mathrm{R}^{2}=0.32\right)$, External factors $\left(\mathrm{R}^{2}=0.20\right)$. In explaining high scores, both on instructive leadership scale and in terms of variance, account should also be taken of the specific nature of the school itself, which was established to educate children of Americans in the diplomatic mission in India, due to the structure of students, teaching and leadership personnel, and environment (this is an extraterritorial school). On the other hand, statistically significant but very low correlation between the dimensions of the instructive leadership style and teacher collaboration was found by Gumus, Bulut and Bellibas (2013). 
A survey of 2970 respondents in 183 schools found that $10 \%$ of teachers' collaboration variance explains the principal's follow-up of the teaching process, while giving feedback, while $7.2 \%$ of the variance is explained by clear setting and expressing common goals. The authors, however, warn of the big differences in the results obtained, depending on the school and the structure of the respondents. This shed light on additional factors that are related to the degree of (self) observed collaboration among teachers, for which a statistically significant coefficient of determination was obtained: gender $\left(\mathrm{R}^{2}=0.054\right)$, working status $\left(\mathrm{R}^{2}=0.051\right)$, school type $\left(\mathrm{R}^{2}=0.21\right)$. The results showed that female teachers are more interested in cooperation than male teachers that teachers with specific contracts are also more likely to work together more closely than teachers with contracts on an indefinite basis, and that teachers in private schools are more likely to cooperate than teachers from public schools. This shows that the issue of collaboration among teachers is also a rather complex construct, as well as innovation in teaching, and it is not realistic to expect that any single factor, including the principal, achieves high association.

At a somewhat similar correlation when it comes to the principal's role in the collaboration of teachers, as was obtained in this study, Silva, Amante and Morgado (2017) pointed out. They have explored the role of elementary school principals, looking at four dimensions of support (support for professional development of teachers, instrumental support / encouragement, support for innovation, and emotional and intelligence support) in the cooperation of teachers. The results showed that $29 \%$ of the variance of teachers' collaboration in the field of recreational and educational activities is explained by the role of the principal (through the collective action of all four dimensions of support), $13 \%$ of the variance of cooperation in activities related to the development of the curriculum and $13 \%$ of the variance of cooperation in interdisciplinary activities.

Using the MLQ to describe the perception of the leadership style of principals, and a somewhat different instrument for obtaining data on the teacher's perception of mutual collaboration, as the dimension of the school climate (SCI-R) Allen, Grigsby and Peters (2015), they also found the connection and predictor value of the idealized impact (attributed) $\left(\mathrm{R}^{2}=0.433\right)$ and the idealized impact (behavior) $\left(\mathrm{R}^{2}=0.445\right)$ with the style of leadership of school principals.
Slightly weaker, but still statistically significant, with the perceived style of leadership of the principal is related part of the pedagogical climate that refers to school resources $\left(\mathrm{R}=0.37 ; \mathrm{R}^{2}=0.12\right)$. This means that $12 \%$ of the variance of school resource perception can be explained by the leadership style of the principal. Considering that no leadership dimension has proven to be a significant predictor of the dependent variable, we conclude that the perception of equipping the school library with books and textbooks, school equipment with teaching resources and aids, video equipment and video content, and the perception of their availability will generally be related to the perceived leadership style of the principal.

The lower correlation between the leadership style of school principals and school resources could result from the fact that schools are not profit-oriented organizations with market orientation, the success of which leaders could be measured, among other things, by material and technical equipment. Although they can be held responsible for the availability of existing resources, to which they referred to two out of a total of four in the instrument, teachers are aware that the school building, working and student residence rooms are maintained from budgetary funds, which, according to the pre-established criteria, are assigned by the founder. Equally it applies to the purchase of teaching resources and supplies. It is true that with their own initiative, through the involvement of schools in various projects of government and non-governmental, domestic and foreign sectors, principals can to some extent contribute to equipping schools, to which teachers have indicated their answers. This leads us to conclude that the principal's role is unquestionable, but less significant for securing resources in relation to the role it plays in teaching and teacher-related innovation. The significance of the role of the principal in creating this dimension of the school climate, probably due to its low connection with the style of leadership, is inferred in only one of all the above studies. Only Tajasom and Ahmad (2011) between transformational leadership style of principals in secondary schools (MLQ), perceived by teachers, and resources as school climate dimensions (SLEQ), found the factor of determination $\mathrm{R}^{2}=0.16$. On the other hand, there is only a slight negative link between transactional style and school resources, for which the determining factor is $\mathrm{R}^{2}=0.034$. This result is similar to the result of our study. 
The relationship between the perceived leadership style and the dimension of the school climate Student Relations has only statistical significance, while there is no practical value, and detailed discussion of the previous cases of connection is detailed, and detailed discussion is unnecessary. We will only emphasize that the relationship between the principal's style of leadership and the relationship teachers have with students was not found in any other analyzes. Although they are an integral part of an instrument that measures the overall climate of the school, the issues contained in the dimension "Student Relations" are directed exclusively to students' behavior towards teachers (most students are respected by teachers; most students are ready to cooperate and provide assistance to teachers; in my school students are wellbehaved, most students are motivated to learn), and it was not realistic to expect that they will significantly contribute directly to the overall picture of the school climate. That the climate at the class level and as the dimension of the teaching process does not exist in a vacuum, but in the context of the overall climate of the school, tells at least a slight association, which strives to a weak one $(\mathrm{R}=0.18)$. Perhaps, for this reason, these results should be taken into account in some future revision of the instrument, and adjust the particles so as to more clearly focus on the relationship of teachers and students in the context of the overall pedagogical climate of the school.

\section{CONCLUSION}

The results obtained in this study indicate the relationship between the perceived leadership style of principals and the experiences of the school climate by teachers. The strongest connection was found in the case of innovation in the work of teachers and their mutual collaboration, as well as climate dimension, with an idealized impact - behavior (dimension of transformational leadership) and Laissez-faire leadership. In addition, the link with Laissez-faire style has a negative sign. The highest explained degree of variance of $24 \%$ indicates that these are two complex variables, which, besides being interconnected, are also conditioned by numerous other factors. Among these, the position of the principals of a elementary school / public institution, which is strongly determined from the outside (the influence of the founders, the way of financing, the obligation of the public work, etc.). However, the results of the research also show that each school is a specific environment, with somewhat different relationships and dynamics of communi- cation and interaction, and it is important to bear in mind the role of the principal in their design, in order to ensure optimal functioning of the school. The most suitable of the three explored leadership styles is the transformational style.

\section{REFERENCES}

Allen, N., Grigsby, B. \& Peters, M. L. (2015). Does leadership matter? Examining the relationship among transformational leadership, school climate, and student achievement. International Journal of Educational Leadership Preparation, Vol. 10, No. 2, pp. 1-22.

Avolio, B. J. \& Bass, B. M. (2002). Developing potential across a full range of leadership: Cases on transactional and transformational leadership. New Jersy: Lawrence Erlbaum associates.

Avolio, B. J. \& Bass, B. M. (2010). Multifactor Leadership Questionnaire (MLQ): manual. Jastrebarsko: Naklada Slap.

Bass, B. M. \& Riggio, R. E. (2006). Transformational leadership, Second edition. New Jersy: Lawrence erlbaum associates

Bass, B. M. (1990). From transactional to transformational leadership: Learning to share the vision. Organization dynamics, 18(3), pp. 19-36

Bass, B. M. (1990). From transactional to transformational leadership: Learning to share the vision. Organization dynamics, 18(3), pp. 19-36.

Bittel, L. R (1997). Leadership: leadership styles and techniques. Beograd: Clio.

Blažević, I. (2014). The leadership role of school principals. School News, 63(1-2), pp. 7-21.

Bognar, L. \& Matijević, M. (2002).Didactics, Second revised edition. Zagreb: School book

Bojanović, R. (2004). Psychology of interpersonal relations, Fifth edition. Beograd: Center for Applied Psychology.

Burns, J. M. (1978). Leadership.New York: Open road integrated media

Cuardado, I. et. al. (2012). Gender differences in leadership styles as a function of leader and subordinates sex and type of organization. Journalof applied psychology, Vol. 42, No. 12, pp. 3083-3113.

Domović, V. (2004). School atmosphere and school performance, Second edition, Jastrebarsko: Naklada Slap.

DuPont, J. P. (2009). Teacher perceptions of the influence of principal instructional leadership on school culture: A case study of the Amrican embassy school in New Dwlhi, India, Phd Thesis, University of Minnesota.

Gumus, S., Bulut, O. \& Bellibas, M. S. (2013). The relationship between principal leadership and teacher collaboration in Turkish primary schools: A multilevel analysis. Education research and perspectives: An international journal, Vol. 40, pp. 1-29.

Johnson, B., Stevens, J. J. \& Zvoch, K. (2007). Teachers' perceptions of school climate: A validity study of scores from the revised school environment questionnaire. Educational and psychological measurement Vol. 67, No 5, pp. 833844. 
Kovač, V., Ledić, J. i Rafajac, B. (2002). Leadership of higher education institutions: Problems and approaches to solutions. Social research, no. 6(62), pp. 1013-1030.

Krech, D., Crutchfield, R. S., \& Ballachey, E. L. (1972). Individual in Society. Belgrade: Institute for Textbooks and Teaching Resources.

Leithwood, K. A. et al. (2006). Successful school leadership: What it is and how it influences pupil learning. Nottingham: National college for school leadership.

Leithwood, K. \& Jantzi, D. (1999). The relative effects of principal and teacher sources of leadership on student engagement with school. Educational Administration Quarterly, 35(5), pp. 679-70

Lewin, K., Lippitt, R. \& White, R. (1939). Patterns of aggressive behaviour in experimentally created ,SOcial climates“. Journal of social psychology 10, pp. 271-301.

Marks, H. M. \&Printy, S. M. (2003). Principal leadership and school performance: An integration of transformational and instructional leadership. Educational administration quarterls, Vol. 39, No. 3, pp. 370397.

McKeever, B. (2003). Nine lessons of successful school leadership teams. San Francisco: WestEd.

McLachlan, G. (2004). Discriminant Analysis and Statistical Pattern Recognition. New York: John Wiley \& Sons.

Menard, S. (1995). Applied logistic regression analysis. Thousand Oaks: Sage, University paper series on quantitative applications in the social sciences.

Ministry of Education, Science, Culture and Sports of the Tuzla Canton (2005). Pedagogical standards and general normative for primary education. Tuzla: MONKS.
Myers, R. (1990). Classical and modern regression with applications. Boston: Duxbury.

Nachmias, R. et. al. (2004). Factors involved in the implementation of pedagogical innovations using technology. Education and information technologies, 9:3, pp. 291-308.

OECD (2007a). Education at a Glance: OECD Indicators 2007. Paris: OECD.

OECD (2007b). PISA 2006: Science Competencies for Tomorrow's World. Paris: OECD.

Pont, B.,Nusche. D. \& Moorman, H (2008). Improving School Leadership, Volume 1: Policy and Practice, OECD: Paris.

Rafferty, T. J. (2003). School climate and teacher attitudes toward upward communication in secondary scholls. American secondary education 31(2), pp. 49-70.

Silva, J. C., Amante, L. \& Morgado, J. (2017). School climate, principal support and collaboration among Portugese teachers. European journal of teacher education 2017, pp. 1-17.

Smith, C. A. B. (1947). Some examples of discrimination. Annals of Eugenics 13, 272-282.

Staničić, S. (2011). Management in Education. GornjiMilanovac: Center for Marketing in Education.

Sušanj, Z. (2005). Organizational climate and culture. Jastrebarsko: Naklada Slap.

Tabachnick, B. G. \&Fidell, L.S. (2012). Using Multivariate Statistics.6th ed. Boston: Allyn and Bacon.

Tajasom, A. \& Ahmad, Z. A. (2011).Principals' leadership style and school climate: teachers' perspectives from Malaysia. The international journal of leadership in public services, Vol. 7, No. 4, 314 - 333. 